\title{
Genetic Association Analysis of Cell Cycle Regulators Reveals YWHAZ Has Prognostic Significance in Prostate Cancer
}

\author{
CHIA-CHENG YU ${ }^{1,2,3^{*}}$, LIH-CHYANG CHEN ${ }^{4 *}$, WEN-HSIN LIN ${ }^{*}$, VICTOR C. LIN $^{6,7}$, CHAO-YUAN HUANG $^{8}$, \\ TE-LING LU ${ }^{5}$, CHENG-HSUEH LEE ${ }^{9,10}$, SHU-PIN HUANG ${ }^{9,10,11,12}$ and BO-YING BAO ${ }^{5,13,14}$ \\ ${ }^{1}$ Division of Urology, Department of Surgery, Kaohsiung Veterans General Hospital, Kaohsiung, Taiwan, R.O.C.; \\ ${ }^{2}$ Department of Urology, School of Medicine, National Yang-Ming University, Taipei, Taiwan, R.O.C.; \\ ${ }^{3}$ Department of Pharmacy, College of Pharmacy and Health Care, Tajen University, Pingtung, Taiwan, R.O.C.; \\ ${ }^{4}$ Department of Medicine, Mackay Medical College, New Taipei City, Taiwan, R.O.C.; \\ ${ }^{5}$ Department of Pharmacy, China Medical University, Taichung, Taiwan, R.O.C.; \\ ${ }^{6}$ Department of Urology, E-Da Hospital, Kaohsiung, Taiwan, R.O.C.; \\ ${ }^{7}$ School of Medicine for International Students, I-Shou University, Kaohsiung, Taiwan, R.O.C.; \\ ${ }^{8}$ Department of Urology, National Taiwan University Hospital, \\ College of Medicine, National Taiwan University, Taipei, Taiwan, R.O.C.; \\ ${ }^{9}$ Department of Urology, Kaohsiung Medical University Hospital, Kaohsiung, Taiwan, R.O.C.; \\ ${ }^{10}$ Graduate Institute of Medicine, College of Medicine, Kaohsiung Medical University, Kaohsiung, Taiwan, R.O.C.; \\ ${ }^{11}$ Department of Urology, Faculty of Medicine, College of Medicine, \\ Kaohsiung Medical University, Kaohsiung, Taiwan, R.O.C.; \\ ${ }^{12}$ Institute of Biomedical Sciences, National Sun Yat-sen University, Kaohsiung, Taiwan, R.O.C.; \\ ${ }^{13}$ Sex Hormone Research Center, China Medical University Hospital, Taichung, Taiwan, R.O.C.; \\ ${ }^{14}$ Department of Nursing, Asia University, Taichung, Taiwan, R.O.C.
}

\begin{abstract}
Background/Aim: This study aimed to identify the genes that cause biochemical recurrence (BCR) following radical prostatectomy $(R P)$ in men with localized prostate cancer. Patients and Methods: A two-stage genetic association study of 19 single-nucleotide polymorphisms in 11 key cell cycle regulation genes was carried out. BCR-free survival after $R P$ was evaluated in a discovery cohort of 458 patients with prostate cancer, and replication was investigated in another cohort of 185 patients. Results: A consistent association was found between BCR and rs2290291 (discovery: $p=0.008$;
\end{abstract}

This article is freely accessible online.

*These Authors contributed equally to this work.

Correspondence to: Shu-Pin Huang, Department of Urology, Kaohsiung Medical University Hospital, 100 Shih-Chuan 1st Road, Kaohsiung 807, Taiwan, R.O.C. Tel: +886 73121101 ext. 6694; Fax: +886 73221033, e-mail: shpihu@yahoo.com.tw; and Bo-Ying Bao, Department of Pharmacy, China Medical University, 91 Hsueh-Shih Road, Taichung 404, Taiwan, R.O.C. Tel: +886 422053366 ext. 5126, Fax: +886 422031075, e-mail: bao@mail.cmu.edu.tw

Key Words: Cell cycle, prostate cancer, recurrence, YWHAZ, biomarker. replication: $p=0.029)$. $r$ s2290291 is located in the tyrosine 3monooxygenase/tryptophan 5-monooxygenase activation protein zeta (YWHAZ), and was predicted to possess a regulatory function that affected YWHAZ expression. Furthermore, YWHAZ expression was frequently up-regulated in advanced tumours, and associated with poorer survival in patients with prostate cancer. Conclusion: YWHAZ rs2290291 was found to be associated with BCR. YWHAZ may function as a putative oncogene during prostate cancer progression.

Prostate cancer is one of the most common cancers occurring in men, and an estimated 31,620 men will die of prostate cancer in the United States in 2019 (1). For the treatment of localized prostate cancer, radical prostatectomy (RP) remains a viable and commonly used option for curative treatment, but approximately 20-40 percent of men experience a biochemical recurrence (BCR) within 10 years after RP (2, 3 ). Owing to the heterogeneous nature of prostate cancer, it is a continuing challenge to determine risk stratification to facilitate a personalized treatment. In addition to the classical clinicopathological features indicating patient prognosis, it is necessary to define the specific genetic and molecular characteristics, which provide a more definitive insight into tumour biology and the optimization of individualized treatment. 
The cell cycle is a sequence of events that regulate the replication, division, differentiation, and death of cells. It is controlled by a set of checkpoints that monitor completion of critical events and a cascade of protein phosphorylation that relays progression to the next stage (4). Dysregulation of this regulatory system is associated with carcinogenesis, tumour growth, metastasis, and the efficacy of anti-cancer treatments (5). Single nucleotide polymorphisms (SNPs) are the most frequent variations in the human genome. Accumulating evidence has demonstrated that SNPs in cell cycle regulators have functional significance and are linked to increased risk of a more aggressive disease in a variety of malignancies, including prostate cancer (6-10). However, little is known about the relationship between SNPs in cell cycle regulatory genes and inter-individual variations in influencing the risk of disease recurrence after prostate cancer surgery.

We hypothesized that genetic variants in the cell cycle regulation pathway might influence prostate cancer progression. Thus, we systematically evaluated the prognostic values of 19 SNPs in 11 key cell cycle regulators in a discovery cohort of 458 prostate cancer patients with BCR and investigated replication in an independent cohort of 185 patients. Further functional analyses supported the involvement of $Y W H A Z$ in prostate cancer progression.

\section{Patients and Methods}

Patient recruitment and data collection. In total, 643 patients were enrolled in the study from three medical centres in Taiwan: Kaohsiung Medical University Hospital, Kaohsiung Veterans General Hospital, and National Taiwan University Hospital, as described previously (11). All patients were unrelated, belonged to the Han Taiwanese population, confirmed to have prostate cancer based on histopathological information, and had undergone RP without adjuvant hormone therapy or radiotherapy. The study population was randomly divided into discovery and replication sets with a 7:3 ratio as shown in Table I, and the positive SNPs found in the discovery set were further confirmed in the replication set to reduce false discovery. Clinical data, including age at diagnosis, prostate-specific antigen (PSA), pathologic Gleason score, stage, surgical margin, and BCR status, were collected from patients' medical records. BCR was defined as two consecutive PSA measurements of $0.2 \mathrm{ng} / \mathrm{ml}$ or more following RP (12-15). BCRfree survival was defined as the time period between the RP and the last follow-up or BCR. The institutional review board of Kaohsiung Medical University Hospital approved this study (IRB no: KMUHIRB-2013132), and all participants provided written informed consent in accordance with the institutional guidelines.

SNP selection and genotyping. Based on the Kyoto Encyclopaedia of Genes and Genomes database, we selected 11 genes involved in cell cycle progression, including BUB1 mitotic checkpoint serine/threonine kinase $(B U B 1)$, BUB1 mitotic checkpoint serine/threonine kinase B $(B U B 1 B)$, cyclin A2 (CCNA2), cyclin B1 $(C C N B 1)$, cyclin B2 (CCNB2), cell division cycle 20 (CDC20),
Table I. Clinicopathologic characteristics of the study populations.

\begin{tabular}{lcc}
\hline Characteristics & Discovery & Replication \\
\hline N of patients & 458 & 185 \\
Age at diagnosis & & \\
$\quad$ Median, years (IQR) & $66(61-70)$ & $66(61-70)$ \\
$<66$ & $211(46.1)$ & $80(43.2)$ \\
$\geq 66$ & $247(53.9)$ & $105(56.8)$ \\
PSA at diagnosis, N (\%) & & \\
$\quad$ Median, ng/ml (IQR) & $11.1(7.1-17.5)$ & $11.0(6.9-18.7)$ \\
Pathologic Gleason score, N (\%) & $392(86.5)$ & $155(85.6)$ \\
$2-7$ & $61(13.5)$ & $26(14.4)$ \\
$8-10$ & & \\
Pathologic stage, N (\%) & $303(67.2)$ & $127(70.6)$ \\
T1/T2 & $148(32.8)$ & $53(29.4)$ \\
T3/T4/N1 & $241(72.6)$ & $104(75.4)$ \\
Surgical margin, N (\%) & $91(27.4)$ & $34(24.6)$ \\
Negative & $184(40.2)$ & $90(48.6)$ \\
Positive & 54 & 74 \\
Biochemical recurrence, N (\%) & \\
Median follow-up, months &
\end{tabular}

IQR: Interquartile range; PSA: prostate-specific antigen.

cyclin-dependent kinase 1 (CDK1), PTTG1 regulator of sister chromatid separation, securing (PTTG1), TTK protein kinase (TTK), tyrosine 3-monooxygenase/tryptophan 5-monooxygenase activation protein gamma (YWHAG), and tyrosine 3-monooxygenase/ tryptophan 5-monooxygenase activation protein zeta (YWHAZ). We initially selected 25 haplotype tagging SNPs (htSNPs) in these genes using SNPinfo (16) with a threshold - minor allele frequency of $>0.05$ in the HapMap CHB (Han Chinese in Beijing) population and a pairwise linkage disequilibrium squared correlation coefficient $\left(r^{2}\right)$ of $>0.8$. Genomic DNA was extracted from the peripheral blood of participants using the QIAamp DNA Blood Mini Kit (Qiagen, Valencia, CA, USA), and SNP genotyping was conducted using Agena Bioscience iPLEX matrix-assisted laser desorption/ionization time-of-flight mass-spectrometry technology at the National Centre for Genome Medicine, Taiwan, as described previously (17). Negative controls and 35 blind duplicates were used to control genotyping quality. The average genotype call rate for SNPs was $99.3 \%$, and the concordance rate was $99.9 \%$. Any SNP that failed the assay design $(N=1)$, having a genotyping call rate of $<80 \%$, and deviated from Hardy-Weinberg equilibrium $(p<0.01, N=4)$, or was non-polymorphic $(N=1)$, was removed, leaving a total of $19 \mathrm{htSNPs}$ for further analyses.

Bioinformatics analysis. We used HaploReg v4.1 (18) to investigate whether the risk SNP, rs2290291, possessed potential regulatory functions. The Genotype-Tissue Expression (GTEx) portal (19) was used to assess the correlation between rs2290291 and YWHAZ mRNA expression. The prognostic effects of $Y W H A Z$ on prostate cancer were analysed using publicly available microarray datasets from Taylor et al. (20), Sboner et al. (21), and The Cancer Genome Atlas (TCGA) (22).

Statistical analysis. Kaplan-Meier analyses and log-rank tests were used to examine differences in BCR-free survival across different 
Table II. Genotyped SNPs and the p-Values of their association with BCR after RP.

\begin{tabular}{|c|c|c|c|c|c|c|c|c|}
\hline \multirow[t]{2}{*}{ Gene } & \multirow[t]{2}{*}{ SNP ID } & \multirow[t]{2}{*}{ Chromosome } & \multirow[t]{2}{*}{ Position } & \multirow[t]{2}{*}{ MAF } & \multirow[t]{2}{*}{ HWE } & \multicolumn{3}{|c|}{ BCR } \\
\hline & & & & & & Additive & Dominant & Recessive \\
\hline$B U B 1$ & rs11900983 & 2 & 110668761 & 0.084 & 0.703 & 0.950 & 0.877 & - \\
\hline$B U B 1 B$ & rs876821 & 15 & 40156498 & 0.213 & 0.642 & 0.406 & 0.656 & - \\
\hline CCNA2 & rs 3217773 & 4 & 121817966 & 0.232 & 0.705 & 0.222 & 0.101 & 0.798 \\
\hline CCNA2 & rs769242 & 4 & 121821062 & 0.060 & 0.988 & 0.357 & 0.393 & - \\
\hline CCNA2 & rs 3217772 & 4 & 121818028 & 0.384 & 0.252 & 0.143 & 0.315 & 0.147 \\
\hline CCNA2 & rs769240 & 4 & 121822912 & 0.231 & 0.591 & 0.038 & 0.246 & - \\
\hline$C C N B 1$ & rs164386 & 5 & 69164575 & 0.458 & 0.507 & 0.871 & 0.221 & 0.264 \\
\hline$C C N B 2$ & rs8039514 & 15 & 59114382 & 0.442 & 0.597 & 0.401 & 0.235 & 0.904 \\
\hline$C D C 20$ & rs710251 & 1 & 43360641 & 0.438 & 0.717 & 0.803 & 0.490 & 0.706 \\
\hline$C D K 1$ & rs 10711 & 10 & 60794716 & 0.361 & 0.391 & 0.478 & 0.606 & 0.496 \\
\hline$C D K 1$ & rs3213067 & 10 & 60790256 & 0.147 & 0.349 & 0.234 & 0.450 & - \\
\hline$C D K 1$ & rs 1060373 & 10 & 60794742 & 0.096 & 0.840 & 0.625 & 0.720 & - \\
\hline PTTG1 & rs 2910200 & 5 & 160422984 & 0.111 & 0.188 & 0.898 & 0.573 & - \\
\hline$T T K$ & rs672372 & 6 & 80037636 & 0.321 & 0.046 & 0.457 & 0.433 & 0.708 \\
\hline TTK & rs 1897870 & 6 & 80010569 & 0.399 & 0.424 & 0.607 & 0.820 & 0.503 \\
\hline$Y W H A G$ & rs 10241401 & 7 & 76346110 & 0.158 & 0.460 & 0.351 & 0.527 & - \\
\hline$Y W H A G$ & rs6465111 & 7 & 76362061 & 0.060 & 0.451 & 0.587 & 0.811 & - \\
\hline$Y W H A Z$ & rs 3134353 & 8 & 100935225 & 0.322 & 1.000 & 0.542 & 0.512 & 0.797 \\
\hline$Y W H A Z$ & rs 2290291 & 8 & 100952672 & 0.490 & 0.026 & 0.008 & 0.005 & 0.157 \\
\hline
\end{tabular}

SNP: Single nucleotide polymorphism; BCR: biochemical recurrence; RP: radical prostatectomy; MAF: minor alleles frequency; HWE: HardyWeinberg equilibrium. $p$-Values for log-rank test; $p<0.05$ are in bold.

genotypes or gene expression groups. Univariate and multivariate Cox regression analyses were used to calculate the crude and adjusted hazard ratios (HRs) and their 95\% confidence intervals (CIs) either without or with adjustment for age, PSA at diagnosis, pathologic Gleason score, stage, and surgical margin. A metaanalysis was performed to combine the normalized effect size of the expression quantitative trait loci (eQTL) in 9745 samples across 43 human tissues from the GTEx database. Statistical analyses were performed using Statistical Package for the Social Sciences software (SPSS), version 19.0.0 (IBM, Armonk, NY, USA). A two-sided $p$ value $<0.05$ was considered statistically significant.

\section{Results}

The baseline clinical and pathological characteristics of patients in the discovery and replication sets are presented in Table I. No significant differences in these clinical features were observed between the discovery and replication sets. PSA at diagnosis, pathologic Gleason score, stage, and surgical margin were significantly associated with BCR-free survival in both sets.

Among the 19 SNPs evaluated in the discovery study, CCNA2 rs769240 and YWHAZ rs2290291 were associated with BCR-free survival ( $p \leq 0.038$, Table II and Figure 1A). This association was consistently observed for $Y W H A Z$ rs2290291 in the replication set $(p=0.029$, Table III and Figure 1B). In a combined analysis, the $Y W H A Z$ rs2290291
$\mathrm{G}>\mathrm{A}$ exhibited adverse outcomes for BCR-free survival, and the association remained significant in multivariate Cox analysis after adjusting for clinical risk factors, including age, PSA at diagnosis, pathologic Gleason score, stage, and surgical margin (adjusted $\mathrm{HR}=1.27,95 \% \mathrm{CI}=1.02-1.59$, $p=0.033$, Table III and Figure 1C).

YWHAZ rs2290291 was not in linkage disequilibrium with other SNPs, and was found to overlap with promoter histone marks, DNase hypersensitivity sites, and protein binding sites in a variety of cell types according to the functional annotation of HaploReg (Table IV). The eQTL was investigated using GTEx data, and a trend was found involving decreased expression of $Y W H A Z$ for rs2290291 A $>\mathrm{G}$ transition in a meta-analysis of 9745 samples across 43 human tissues $(p<0.001$, Figure 2A). These findings indicated that up-regulation of $Y W H A Z$ expression in individuals carrying rs2290291A might result in the observed association with worse BCR-free survival.

To evaluate the role of $Y W H A Z$ in prostate cancer, we investigated the association between the $Y W H A Z$ expression and prostate cancer prognosis using TCGA datasets. Upregulation of $Y W H A Z$ expression was found to be correlated with higher Gleason scores and advanced stage tumours $(p<0.001$, Figures 2B and C). Patients with a higher expression of $Y W H A Z$ also had significantly poorer overall survival than those with lower expression $(p=0.019$, Figure 

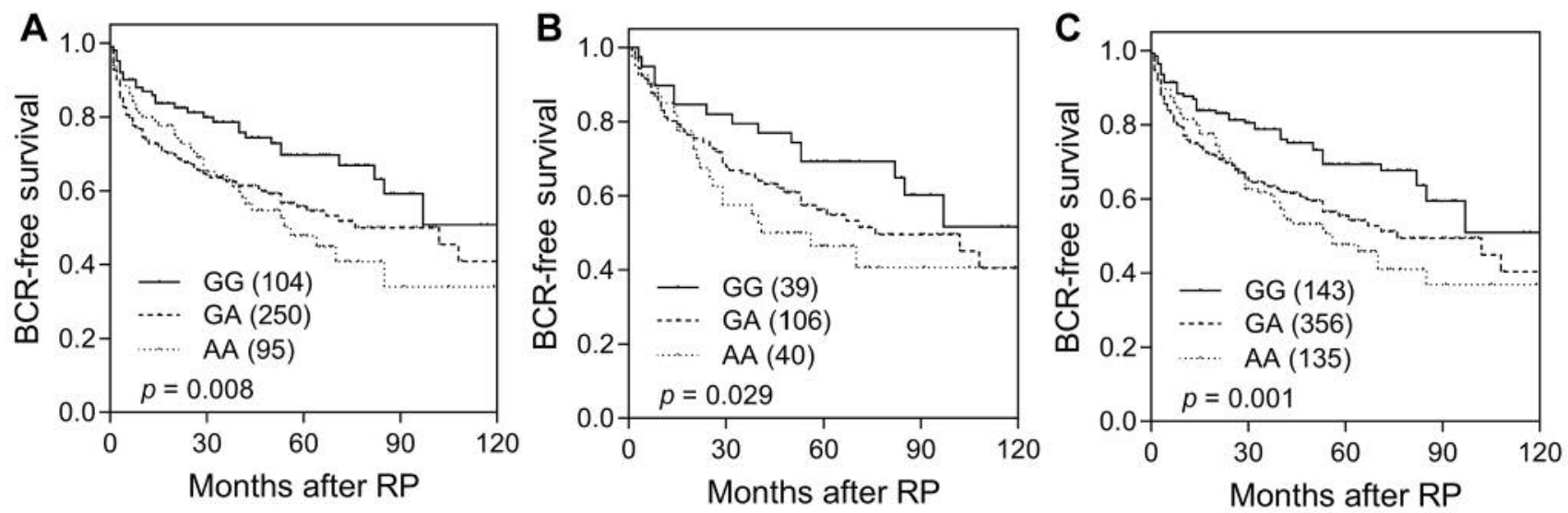

Figure 1. Kaplan-Meier survival curves of biochemical recurrence-free survival, according to YWHAZ rs2290291 genotypes in the (A) discovery set, $(B)$ replication set, and $(C)$ combined analysis. Numbers in parentheses indicate the number of patients.

Table III. SNPs associated with BCR in prostate cancer patients receiving RP.

\begin{tabular}{|c|c|c|c|c|c|c|c|c|c|c|}
\hline \multirow{2}{*}{$\begin{array}{l}\text { Gene SNP } \\
\text { Genotype }\end{array}$} & \multicolumn{5}{|c|}{ Discovery } & \multicolumn{2}{|c|}{ Replication } & \multicolumn{3}{|l|}{ Combined } \\
\hline & $\mathrm{N}$ & $\mathrm{BCR}$ & $p$-Value & $\mathrm{N}$ & $\mathrm{BCR}$ & $p$-Value & HR $(95 \% \mathrm{CI})$ & $p$-Value & HR $(95 \% C I)^{a}$ & $p$-Value ${ }^{\mathrm{a}}$ \\
\hline \multicolumn{11}{|l|}{$C C N A 2$ rs769240 } \\
\hline $\mathrm{AA}$ & 264 & 99 & & 114 & 53 & & & & & \\
\hline $\mathrm{AC}$ & 167 & 66 & & 64 & 33 & & & & & \\
\hline $\mathrm{CC}$ & 22 & 15 & & 7 & 4 & & & & & \\
\hline $\mathrm{AC} / \mathrm{CC} v s . \mathrm{AA}$ & & & 0.246 & & & 0.730 & & & & \\
\hline Trend & & & 0.038 & & & 0.713 & & & & \\
\hline \multicolumn{11}{|l|}{$Y W H A Z$ rs2290291 } \\
\hline GG & 104 & 30 & & 39 & 15 & & 1.00 & & 1.00 & \\
\hline GA & 250 & 103 & & 106 & 52 & & $1.64(1.18-2.29)$ & 0.004 & $1.56(1.04-2.34)$ & $\mathbf{0 . 0 3 3}$ \\
\hline $\mathrm{AA}$ & 95 & 45 & & 40 & 23 & & $1.91(1.31-2.79)$ & 0.001 & $1.68(1.05-2.68)$ & 0.031 \\
\hline GA/AA vs. GG & & & 0.005 & & & 0.108 & $1.71(1.24-2.36)$ & 0.001 & $1.59(1.07-2.36)$ & 0.021 \\
\hline AA $v s . \mathrm{GG} / \mathrm{GA}$ & & & 0.157 & & & 0.062 & $1.33(1.01-1.75)$ & 0.042 & $1.21(0.86-1.72)$ & 0.281 \\
\hline Trend & & & 0.008 & & & 0.029 & $1.36(1.14-1.62)$ & 0.001 & $1.27(1.02-1.59)$ & 0.033 \\
\hline
\end{tabular}

SNP: Single nucleotide polymorphism; BCR: biochemical recurrence; MST: median BCR-free survival time; RP: radical prostatectomy; HR: hazard ratio; CI: confidence interval. aAdjustment for age, PSA at diagnosis, pathologic Gleason score, stage, and surgical margin. $p<0.05$ are in bold.

2D). Consistently, there was a correlation of higher $Y W H A Z$ expression with decreased overall and BCR-free survival in another two independent prostate cancer microarray datasets $(p \leq 0.012$, Figures $2 \mathrm{E}$ and $\mathrm{F})$.

\section{Discussion}

We conducted a two-stage study to identify the association between genetic variants in the cell cycle regulation pathway and prognosis of prostate cancer patients following RP. YWHAZ rs2290291 was consistently associated with BCRfree survival across both stages of the study. According to the GTEx dataset, rs2290291 is an eQTL that affects the expression of YWHAZ. Importantly, YWHAZ overexpression was observed in most advanced cancer tissues and correlated with shorter survival rates for prostate cancer patients.

YWHAZ, also known as 14-3-3 $\}$, belongs to the 14-3-3 protein family, which mediates signal pathways and controls many biological processes, including protein trafficking, metabolism, cell proliferation, migration, apoptosis, and cell cycle regulation, by binding to phospho-serine/threonine containing proteins (23). Elevated expression of $Y W H A Z$ has been linked to aggressive tumours, drug resistance, and poor prognosis in a variety of tumour types, including prostate 
A

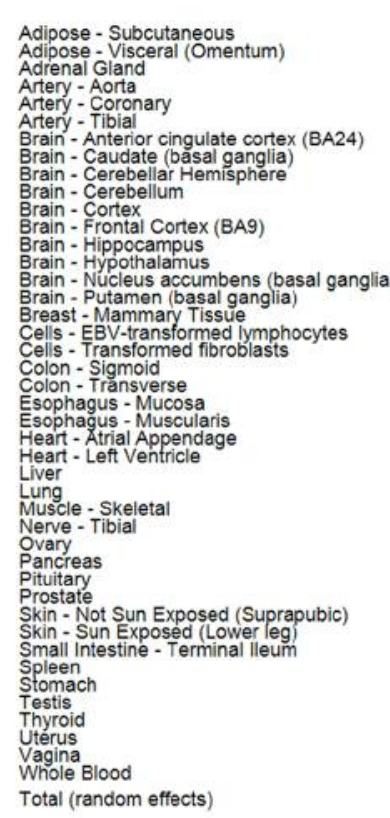

Total (random effects)

\section{B}

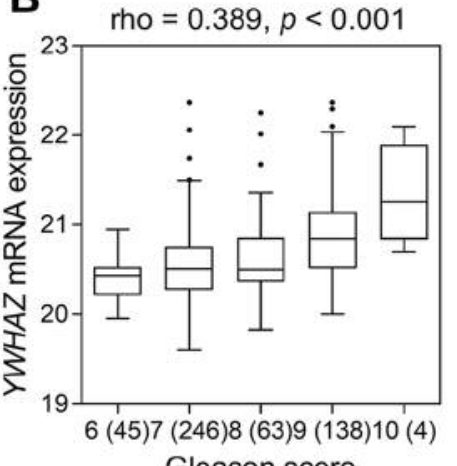

Gleason score

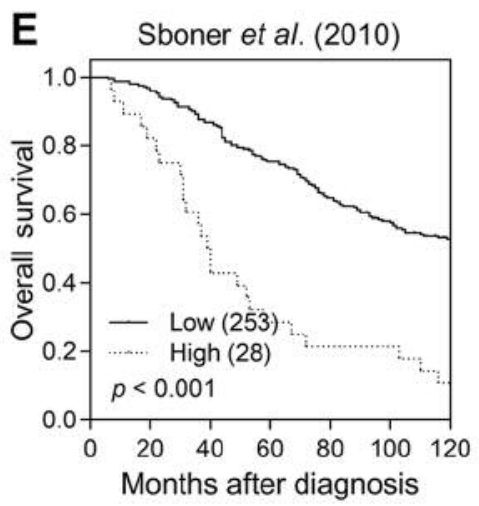

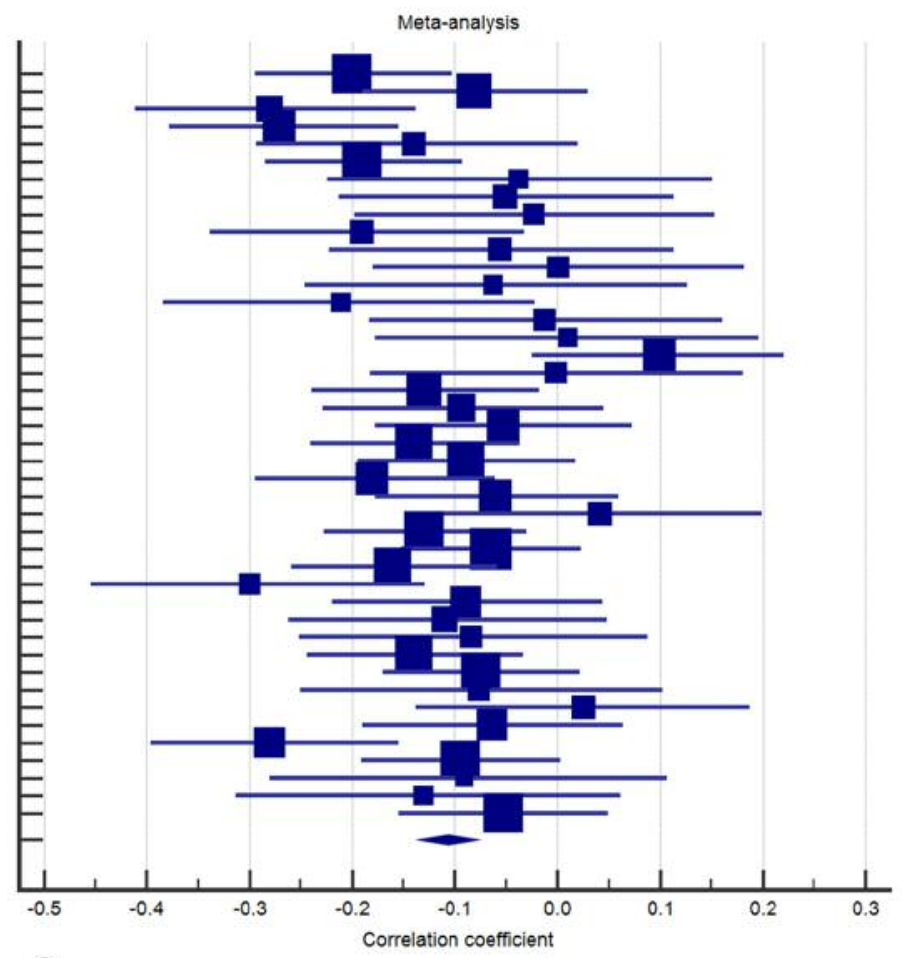

C

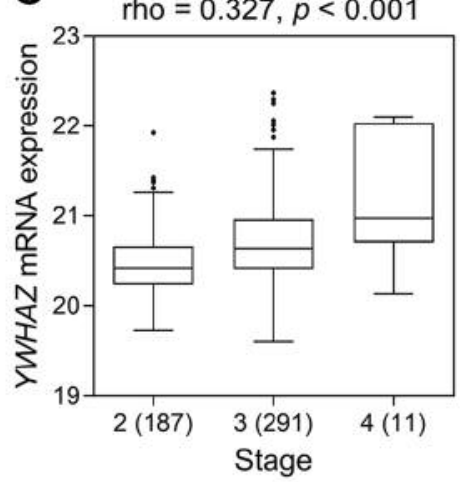

D TCGA (2016)

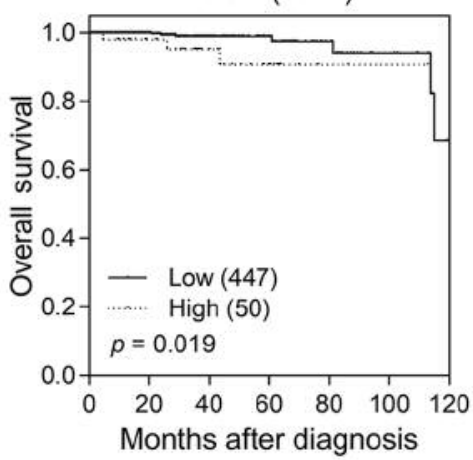

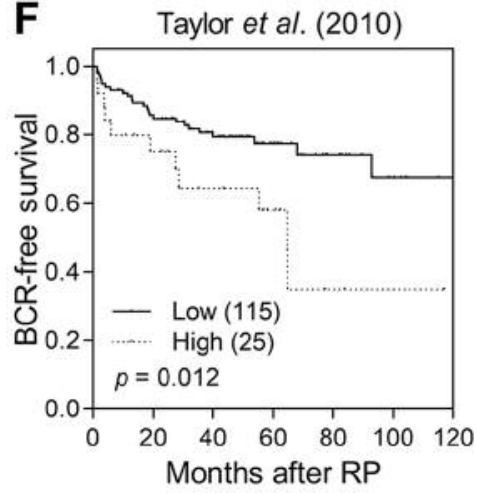

Figure 2. Functional analyses of YWHAZ rs2290291. (A) Forest plot for meta-analysis of the correlation between rs2290291 and YWHAZ expression in 9745 tissue samples from the GTEx dataset. Correlation of YWHAZ expression with prostate cancer progression. (B) High Gleason score and (C) high stage prostate cancers displayed significantly higher mRNA expression. Increased YWHAZ expression was significantly associated with poor (D) overall survival in the TCGA dataset, $(E)$ overall survival in the dataset from Sboner et al. (2010), and $(F)$ BCR-free survival in the dataset from Taylor et al. (2010). Patients were classified into low-and high-risk groups by an optimization algorithm for the minimum p-value. Numbers in parentheses indicate the number of patients. Rho: Spearman's rank correlation coefficient. 
Table IV. Regulatory annotation of YWHAZ rs2290291.

\begin{tabular}{|c|c|c|c|c|c|c|c|c|c|c|}
\hline Chromosome & Position & $\begin{array}{l}\mathrm{LD} \\
\left(\mathrm{r}^{2}\right)\end{array}$ & $\begin{array}{l}\text { SNP } \\
\text { ID }\end{array}$ & $\begin{array}{l}\text { Reference } \\
\text { allele }\end{array}$ & $\begin{array}{l}\text { Alternate } \\
\text { allele }\end{array}$ & $\begin{array}{c}\text { ASN } \\
\text { frequency }\end{array}$ & $\begin{array}{c}\text { Promoter } \\
\text { histone marks }\end{array}$ & $\begin{array}{c}\text { DNAse } \\
\text { hypersensitivity }\end{array}$ & $\begin{array}{l}\text { Proteins } \\
\text { bound }\end{array}$ & $\begin{array}{c}\text { dbSNP } \\
\text { function } \\
\text { annotation }\end{array}$ \\
\hline 8 & 100952672 & 1 & rs 2290291 & A & G & $\begin{array}{r}0.38 \\
\mathrm{~F} \\
\end{array}$ & $\begin{array}{c}\text { ESC, ESDR, LNG, } \\
\text { IPSC, FAT, STRM, } \\
\text { BRST, BLD, MUS, } \\
\text { BRN, SKIN, VAS, } \\
\text { LIV, GI, ADRL, KID, } \\
\text { PANC, PLCNT, THYM, } \\
\text { HRT, OVRY, SPLN, } \\
\text { CRVX, BONE }\end{array}$ & $\begin{array}{l}\text { ESC, ESDR, ESDR, } \\
\text { ESDR, ESDR, ESC, } \\
\text { LNG, IPSC, IPSC, } \\
\text { BRST, BLD, BLD, } \\
\text { BLD, BLD, BLD, } \\
\text { BLD, BLD, SKIN, } \\
\text { SKIN, SKIN, SKIN, } \\
\text { ADRL, BRN, BRN, } \\
\text { HRT, GI, GI, KID, } \\
\text { LNG, MUS, MUS, } \\
\text { PLCNT, GI, THYM, } \\
\text { GI, OVRY, PANC, } \\
\text { MUS, GI, LNG, } \\
\text { BLD, CRVX, LIV, } \\
\text { BRST, MUS, MUS, } \\
\text { VAS, BLD, BLD, } \\
\text { BRN, SKIN, } \\
\text { SKIN, LNG }\end{array}$ & $\begin{array}{c}\text { POL2, } \\
\text { YY1 }\end{array}$ & $\begin{array}{l}Y W H A Z \\
\text { intronic }\end{array}$ \\
\hline
\end{tabular}

LD: Linkage disequilibrium; SNP: single nucleotide polymorphism; ASN: East Asia.

cancer (24). Further, increased frequency of $Y W H A Z$ gene amplification in castration-resistant prostate cancer was found, when compared with localized disease (25). YWHAZ has been shown to be a direct androgen-responsive gene (26). Increased expression of $Y W H A Z$ promoted prostate cancer cell proliferation, migration, survival, and resistance to apoptosis, whereas $Y W H A Z$ knock-down significantly affected cancer cell aggressiveness $(25,27)$. Mechanistic studies have found that YWHAZ possessed oncogenic potential through interaction with a large group of regulatory proteins that were critical for cell proliferation and survival, such as PI3K, FOXO3a, BAD, and Raf-1 (28-30). Activation of PI3K/AKT signalling has been shown to promote cell survival by phosphorylation of FOXO3a, cytoplasmic sequestration of FOXO3a by binding YWHAZ, and consequently prevention of FOXO3a-induced proapoptotic transcriptional regulation (31). HaploReg data suggested that the genomic region containing the risk SNP rs2290291 might be regulatory, and rs2290291 was not in linkage disequilibrium with other SNPs, which indicated that this variant itself could play a role in prostate cancer. Therefore, rs2290291 could affect $Y W H A Z$ expression and influence PI3K/AKT/FOXO3a signalling, ultimately having an impact on prostate cancer cell survival. However, the exact role of YWHAZ in prostate cancer progression requires clarification in future studies.

There were some limitations in this study. The relatively small sample size of both cohorts did not allow for a more stringent level of statistical significance. Both of the study cohorts were Taiwanese; therefore, our findings may not be generalized to other ethnicities. There may be some other important cell cycle regulation genes that contributed to prostate cancer progression, which were not evaluated in this study. We were unable to provide proof that $Y W H A Z$ rs2290291 affected BCR in our study populations because the target tissues of the study participants were unavailable, thus warranting further study.

In summary, by using genetic association analysis and functional analyses, we highlighted the importance of $Y W H A Z$ in prostate cancer patient prognosis. Our results suggested that rs2290291 G>A may increase $Y W H A Z$ expression, resulting in poor prognosis, and could be a potential biomarker to predict clinical outcomes of RP in prostate cancer. However, the detailed molecular mechanisms underlying the role of $Y W H A Z$ in prostate cancer progression require further investigation.

\section{Conflicts of Interest}

The Authors declare that they have no conflicts of interest in regard to this study.

\section{Authors' Contributions}

C-CY, L-CC, W-HL, S-PH, and B-YB conceptualized and designed the study. L-CC, W-HL, T-LL, and C-HL performed the experiments. $\mathrm{C}-\mathrm{CY}, \mathrm{VL}, \mathrm{C}-\mathrm{YH}$, and S-PH coordinated and supervised data collection. VL, C-YH, and B-YB performed the analysis. All the Authors drafted, reviewed and approved the manuscript. 


\section{Acknowledgements}

This work was supported by the Ministry of Science and Technology of Taiwan (grant nos: 105-2314-B-650-003-MY3, 107-2320-B-039010, 108-2813-C-039-148-B, 108-2314-B-037-029, 108-2314-B-037026-MY2, and 108-2320-B-039-050-MY3), the Kaohsiung Medical University Hospital (grant no: KMUH108-8P53 and KMUH1088R55), the E-Da Hospital (grant nos: EDPJ105054, EDPJ106038, and EDPJ107032), and the China Medical University (grant no: CMU107S-42, CMU108-SR-121, and CMU108-MF-50). The funders had no role in the study design, data collection and analysis, decision to publish, or preparation of the manuscript. The Authors would like to thank Chao-Shih Chen for data analysis, and the National Center for Genome Medicine, Ministry of Science and Technology of Taiwan, for technical support. The results published here are based in part on data generated by the HaploReg, GTEx, and TCGA projects.

\section{References}

1 Siegel RL, Miller KD and Jemal A: Cancer statistics, 2019. CA Cancer J Clin 69(1): 7-34, 2019. PMID: 30620402. DOI: $10.3322 /$ caac. 21551

2 Freedland SJ, Humphreys EB, Mangold LA, Eisenberger M, Dorey FJ, Walsh PC and Partin AW: Risk of prostate cancerspecific mortality following biochemical recurrence after radical prostatectomy. JAMA 294(4): 433-439, 2005. PMID: 16046649. DOI: $10.1001 /$ jama.294.4.433

3 Roehl KA, Han M, Ramos CG, Antenor JA and Catalona WJ: Cancer progression and survival rates following anatomical radical retropubic prostatectomy in 3,478 consecutive patients: Long-term results. J Urol 172(3): 910-914, 2004. PMID: 15310996. DOI: 10.1097/01.ju.0000134888.22332.bb

4 Morgan DO: Principles of cdk regulation. Nature 374(6518): 131-134, 1995. PMID: 7877684. DOI: 10.1038/374131a0

5 Elledge SJ: Cell cycle checkpoints: Preventing an identity crisis. Science 274(5293): 1664-1672, 1996. PMID: 8939848. DOI: 10.1126/science.274.5293.1664

6 Henner WD, Evans AJ, Hough KM, Harris EL, Lowe BA and Beer TM: Association of codon 72 polymorphism of p53 with lower prostate cancer risk. Prostate 49(4): 263-266, 2001. PMID: 11746272. DOI: $10.1002 /$ pros. 10021

7 Huang SP, Wu WJ, Chang WS, Wu MT, Chen YY, Chen YJ, Yu $\mathrm{CC}, \mathrm{Wu}$ TT, Lee YH, Huang JK and Huang CH: P53 codon 72 and p21 codon 31 polymorphisms in prostate cancer. Cancer Epidemiol Biomarkers Prev 13(12): 2217-2224, 2004. PMID: 15598783

8 Kibel AS, Ahn J, Isikbay M, Klim A, Wu WS, Hayes RB, Isaacs WB and Daw EW: Genetic variants in cell cycle control pathway confer susceptibility to aggressive prostate carcinoma. Prostate 76(5): 479-490, 2016. PMID: 26708993. DOI: 10.1002/pros.23139

9 Kibel AS, Jin CH, Klim A, Luly J, K AR, Wu WS and Suarez BK: Association between polymorphisms in cell cycle genes and advanced prostate carcinoma. Prostate 68(11): 1179-1186, 2008. PMID: 18459109. DOI: 10.1002/pros.20784

10 Wang L, Habuchi T, Mitsumori K, Li Z, Kamoto T, Kinoshita H, Tsuchiya N, Sato K, Ohyama C, Nakamura A, Ogawa O and Kato $\mathrm{T}$ : Increased risk of prostate cancer associated with aa genotype of cyclin d 1 gene a870g polymorphism. Int J Cancer 103(1): 116120, 2003. PMID: 12455063. DOI: 10.1002/ijc.10793
11 Huang SP, Huang LC, Ting WC, Chen LM, Chang TY, Lu TL, Lan YH, Liu CC, Yang WH, Lee HZ, Hsieh CJ and Bao BY: Prognostic significance of prostate cancer susceptibility variants on prostate-specific antigen recurrence after radical prostatectomy. Cancer Epidemiol Biomarkers Prev 18(11): 3068-3074, 2009. PMID: 19900942. DOI: 10.1158/1055-9965.EPI-09-0665

12 Freedland SJ, Sutter ME, Dorey F and Aronson WJ: Defining the ideal cutpoint for determining psa recurrence after radical prostatectomy. Prostate-specific antigen. Urology 61(2): 365-369, 2003. PMID: 12597949. DOI: 10.1016/s0090-4295(02)02268-9

13 Huang CY, Huang SP, Lin VC, Yu CC, Chang TY, Juang SH and Bao BY: Genetic variants in the hippo pathway predict biochemical recurrence after radical prostatectomy for localized prostate cancer. Sci Rep 5: 8556, 2015. PMID: 25707771. DOI: 10.1038/srep08556

14 Huang EY, Chang YJ, Huang SP, Lin VC, Yu CC, Huang CY, Yin HL, Chang TY, Lu TL and Bao BY: A common regulatory variant in slc35b4 influences the recurrence and survival of prostate cancer. J Cell Mol Med 22(7): 3661-3670, 2018. PMID: 29682886. DOI: $10.1111 /$ jcmm.13649

15 Huang SP, Levesque E, Guillemette C, Yu CC, Huang CY, Lin VC, Chung IC, Chen LC, Laverdiere I, Lacombe L, Fradet Y, Chang TY, Lee HZ, Juang SH and Bao BY: Genetic variants in micrornas and microrna target sites predict biochemical recurrence after radical prostatectomy in localized prostate cancer. Int J Cancer 135(11): 2661-2667, 2014. PMID: 24740842. DOI: $10.1002 / \mathrm{ijc} .28904$

$16 \mathrm{Xu} \mathrm{Z}$ and Taylor JA: Snpinfo: Integrating gwas and candidate gene information into functional snp selection for genetic association studies. Nucleic Acids Res 37(suppl_2): W600-605, 2009. PMID: 19417063. DOI: 10.1093/nar/gkp290

17 Huang CN, Huang SP, Pao JB, Hour TC, Chang TY, Lan YH, Lu TL, Lee HZ, Juang SH, Wu PP, Huang CY, Hsieh CJ and Bao BY: Genetic polymorphisms in oestrogen receptor-binding sites affect clinical outcomes in patients with prostate cancer receiving androgen-deprivation therapy. J Intern Med 271(5): 499-509, 2012. PMID: 21880074. DOI: 10.1111/j.13652796.2011.02449.x

18 Ward LD and Kellis M: Haploreg v4: Systematic mining of putative causal variants, cell types, regulators and target genes for human complex traits and disease. Nucleic Acids Res 44(D1): D877-881, 2016. PMID: 26657631. DOI: 10.1093/nar/gkv1340

19 Consortium GT: The genotype-tissue expression (gtex) project. Nat Genet 45(6): 580-585, 2013. PMID: 23715323. DOI: $10.1038 / \mathrm{ng} .2653$

20 Taylor BS, Schultz N, Hieronymus H, Gopalan A, Xiao Y, Carver BS, Arora VK, Kaushik P, Cerami E, Reva B, Antipin Y, Mitsiades N, Landers T, Dolgalev I, Major JE, Wilson M, Socci ND, Lash AE, Heguy A, Eastham JA, Scher HI, Reuter VE, Scardino PT, Sander C, Sawyers CL and Gerald WL: Integrative genomic profiling of human prostate cancer. Cancer Cell 18(1): 11-22, 2010. PMID: 20579941. DOI: 10.1016/j.ccr.2010.05.026

21 Sboner A, Demichelis F, Calza S, Pawitan Y, Setlur SR, Hoshida Y, Perner S, Adami HO, Fall K, Mucci LA, Kantoff PW, Stampfer M, Andersson SO, Varenhorst E, Johansson JE, Gerstein MB, Golub TR, Rubin MA and Andren O: Molecular sampling of prostate cancer: A dilemma for predicting disease progression. BMC Med Genomics 3: 8, 2010. PMID: 20233430. DOI: $10.1186 / 1755-8794-3-8$ 
22 Cancer Genome Atlas Research N: Comprehensive genomic characterization defines human glioblastoma genes and core pathways. Nature 455(7216): 1061-1068, 2008. PMID: 18772890. DOI: $10.1038 /$ nature 07385

23 Aitken A: 14-3-3 proteins: A historic overview. Semin Cancer Biol 16(3): 162-172, 2006. PMID: 16678438. DOI: 10.1016/ j.semcancer.2006.03.005

24 Neal CL and Yu D: 14-3-3zeta as a prognostic marker and therapeutic target for cancer. Expert Opin Ther Targets 14(12): 1343-1354, 2010. PMID: 21058923. DOI: 10.1517/14728222. 2010.531011

25 Menon R, Deng M, Ruenauver K, Queisser A, Peifer M, Offermann A, Boehm D, Vogel W, Scheble V, Fend F, Kristiansen G, Wernert N, Oberbeckmann N, Biskup S, Rubin MA, Shaikhibrahim Z and Perner S: Somatic copy number alterations by whole-exome sequencing implicates ywhaz and ptk2 in castration-resistant prostate cancer. J Pathol 231(4): 505516, 2013. PMID: 24114522. DOI: 10.1002/path.4274

26 Murata T, Takayama K, Urano T, Fujimura T, Ashikari D, Obinata D, Horie-Inoue K, Takahashi S, Ouchi Y, Homma Y and Inoue S: 14-3-3zeta, a novel androgen-responsive gene, is upregulated in prostate cancer and promotes prostate cancer cell proliferation and survival. Clin Cancer Res 18(20): 5617-5627, 2012. PMID: 22904106. DOI: 10.1158/1078-0432.CCR-12-0281

27 Goc A, Abdalla M, Al-Azayzih A and Somanath PR: Rac1 activation driven by 14-3-3zeta dimerization promotes prostate cancer cell-matrix interactions, motility and transendothelial migration. PLoS One 7(7): e40594, 2012. PMID: 22808202. DOI: $10.1371 /$ journal.pone.0040594
28 Brunet A, Bonni A, Zigmond MJ, Lin MZ, Juo P, Hu LS, Anderson MJ, Arden KC, Blenis J and Greenberg ME: Akt promotes cell survival by phosphorylating and inhibiting a forkhead transcription factor. Cell 96(6): 857-868, 1999. PMID: 10102273. DOI: $10.1016 / \mathrm{s} 0092-8674(00) 80595-4$

29 Datta SR, Katsov A, Hu L, Petros A, Fesik SW, Yaffe MB and Greenberg ME: 14-3-3 proteins and survival kinases cooperate to inactivate bad by bh3 domain phosphorylation. Mol Cell 6(1): 41-51, 2000. PMID: 10949026.

$30 \mathrm{Fu} \mathrm{H}$, Xia K, Pallas DC, Cui C, Conroy K, Narsimhan RP, Mamon H, Collier RJ and Roberts TM: Interaction of the protein kinase raf-1 with 14-3-3 proteins. Science 266(5182): 126-129, 1994. PMID: 7939632. DOI: 10.1126/science.7939632

31 Porter GW, Khuri FR and Fu H: Dynamic 14-3-3/client protein interactions integrate survival and apoptotic pathways. Semin Cancer Biol 16(3): 193-202, 2006. PMID: 16697216. DOI: 10.1016/j.semcancer.2006.03.003
Received November 25, 2019

Revised December 3, 2019

Accepted December 4, 2019 